\title{
THE ANATOMY OF THE AUTONOMIC NERVOUS SYSTEM IN THE DOG ${ }^{1}$
}

\author{
NICHOLAS JAMES MIZERES * \\ Department of Anatomy, University of Michigan School of Medicine, \\ Ann Arbor, Michigan \\ ELEVEN FIGURES
}

INTRODUCTION

Knowledge derived from experiments on the dog has not infrequently been applied to man without considering difierences in anatomy. This is especially true of the autonomic nervous system, only parts of which have been described in the adult dog. The cardiac nerves were described by Schurawlew ('27) and Nonidez ('39), the general plan of the abdominal and sacral regions by Trumble ('34), the lumbosacral trunk by Mehler, Fischer and Alexander ('52), the vagi by Hilsabeck and Hill ('50) and Mecrea and D'Arcy ('25), and the turogenital plexuses by Schabadasch ('26) and Medowar ('25). The present study was undertaken to fill gaps in previous descriptions and to present an over-all view of the autonomic nervous system in the dog, excluding the cephalic region. In the present investigation the NK terminology has been used instead of the usual BNA familiar in human anatomy because the study was based on the dog. Since a $\log$ is a pronograde mammal the terms cranial and caudal seem more appropriate than the BNA terms superior and inferior.

\footnotetext{
${ }^{1}$ This paper is a condensation of a dissertation subnitted in partial fulfillment of the requirements for the degree of Doctor of Plilosophy in the University of Nichigan. I wish to thank Dr. R. T. Woodburne for his interest and advice. For the supply of material the author wishes to express lis appreciation to members of the Departments of Physiology and Pharmacology of the University of Michigan.

2Present address: Department of Anatomy, Wayne University School of Medicine, Detroit, Michigan.
} 
Ten adult dogs, 6 males and 4 females, were injected with embalming fluid soon after death. In 4 specimens red lead was added to facilitate dissection of small arteries. The cardiac region was dissected with the aid of a binocular dissecting microscope.

DESCRIPTION

The cervical region

Nonidez' ('31) study of this region in the puppy is probably the most detailed work in the dog. Both Nonidez ('31) and Finkelstein (1880) described the origin of the depressor nerve in this area but I failed to find a nerve which would fit their descriptions. It may possibly be very closely incorporated in the sheath of the vagus nerve near the nodose ganglion.

1. The cranial cervical ganglion (fig. 1). The cranial cervical ganglion is a large fusiform mass lying adjacent to the origin of the internal carotid artery and deep to the lower margin of the auditory bulla. It is crossed ventrally by the nerve to the carotid sinus and the pharyngeal ramus of the vagus nerve. Its caudal portion lies dorsal to the auricular and occipital arteries and the bifurcation of the common carotid artery. The nodose ganglion lies caudolateral to it. I was able to observe inconstant connections to the 9 th, $11 \mathrm{th}$, and 12 th eranial nerves. A connection to the vagus nerve, just above the nodose ganglion, was observed in all 10 specimens.

The internal carotid nerve (fig. 1) arises from the cranial pole of the cranial cervical ganglion and lies in close relation to the internal carotid artery as it enters its canal. The artery is convoluted while in the canal and filaments from the internal carotid nerve were observed entering the adventitia of the artery.

A large nerve (fig. 1) emerges from the caudal pole of the cranial cervical ganglion and forms a dense plexus which 
follows the branches of the external carotid artery. A short thick branch was also observed joining the pharyngeal ramus of the vagus nerve. Nonidez ('31) regarded this branch as entering the "inferior pharyngeal ramus" of the vagus nerve. In the specimens I examined the superior and inferior pharyugeal rami were given off after this sympathetic comnection entered a "common" pharyngeal ramus.

A thin filament arose from the eentral portion of the cranial cervical ganglion, coursed behind the internal carotid artery and nodose ganglion and entered the first cervical nerve (fig. 1). In three specimens this communicating ramus sent additional fibers to the second and third eervical nerves and to the descending eervical nerve, when present. In three of the 10 cases this ramus was absent.

Caudally the sympathetic trunk joins the vagus nerve just below the nodose ganglion (fig. 1). In 4 specimens the cranial cervical ganglion was observed separated from the nodose ganglion bilaterally but in 6 specimens they were connected with short strands ranging from multiple filaments to almost complete fusion.

A thick mass of fibers arising from the caudal pole of the eranial cervical ganglion and lying on the bifureation of the common carotid artery gives rise to numerous short and long dorsal filaments. The short filaments ramify on the wall of the carotid sinus or bulb and common carotid artery. The long filaments comprise two sets. One group courses on the dorsal wall of the common earotid artery and ramifies on all parts of the more caudal portion of the artery. The second group comprises what Nonidez ('31) calls the thyroid nerve (fig. 1). Fusion of these filaments is variable and in only 4 of my specimens was a single nerve observed. The thyroin nerve descends toward the thyroid artery as a plexus (fig. 1) which receives an anastomotic filament from the external laryngeal nerve and follows the artery directly into the thyroid gland. According to Nonidez ('31) the thyroid gland of the dog is innervated by the cranial cervical ganglion and the recurrent laryngeal nerve. I was able in all cases to find 
recurrent filaments entering the gland. In 4 cases some of the terminal branches of the recurrent laryngeal nerve mingled with filaments of the thyroid plexus.

2. The angosympathetic trunk. In the course of dissection, it was observed that incision of the connective tissue sheath surrounding both vagus and sympathetic trunks allowed their separation. By this "sheath dissection" it was

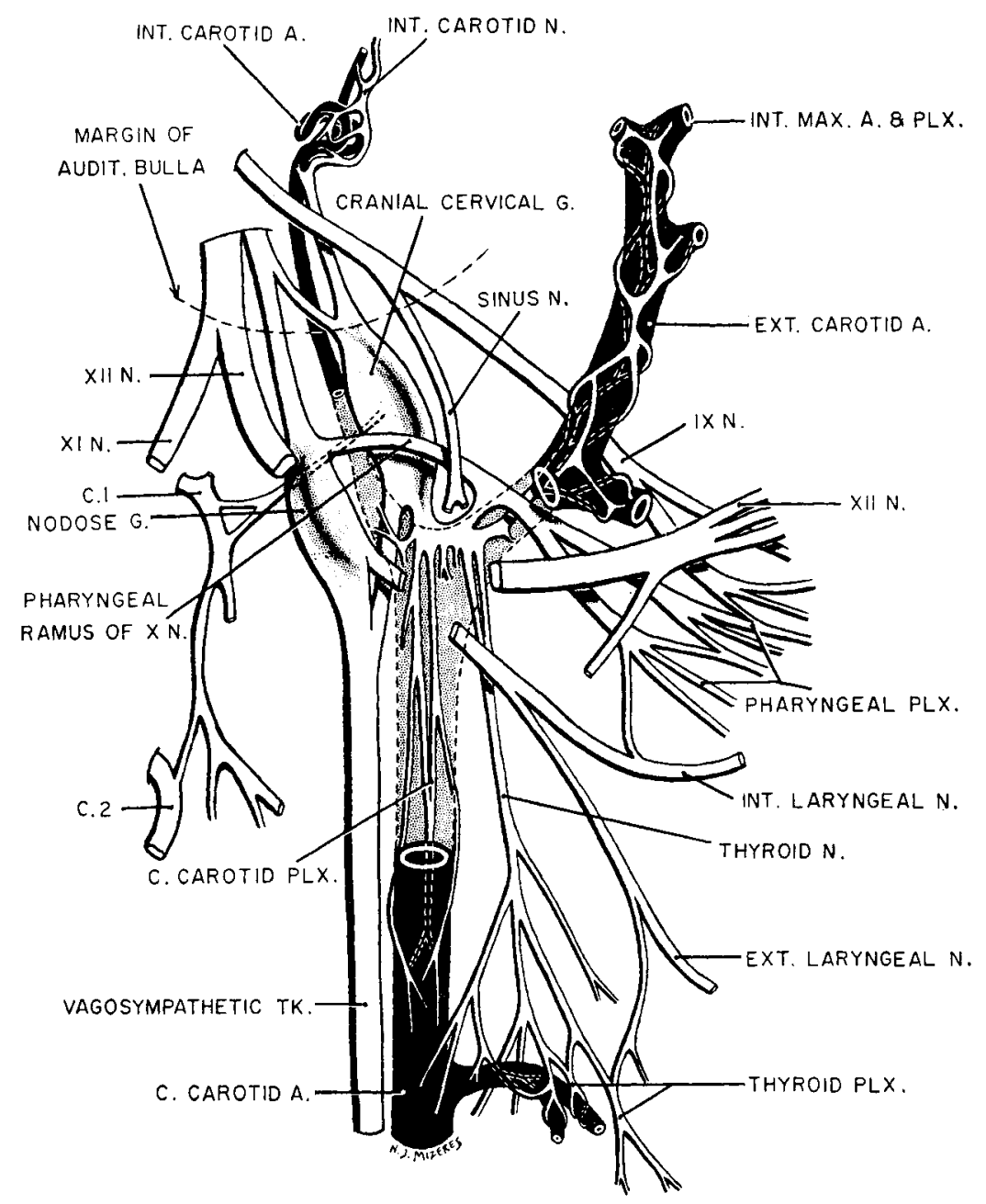

Fig. 1 The cranial cervical region and the thyroid plexas. 
found that both trunks actually separate a few centimeters cophalad to the caudal cervical ganglion (fig. $2 \mathrm{E}$ ). In the cranial portion of the neck the vagus nerve and sympathetic trunk are completely fused. To make certain this separation and fusion was not an artifact of dissection, serial sections
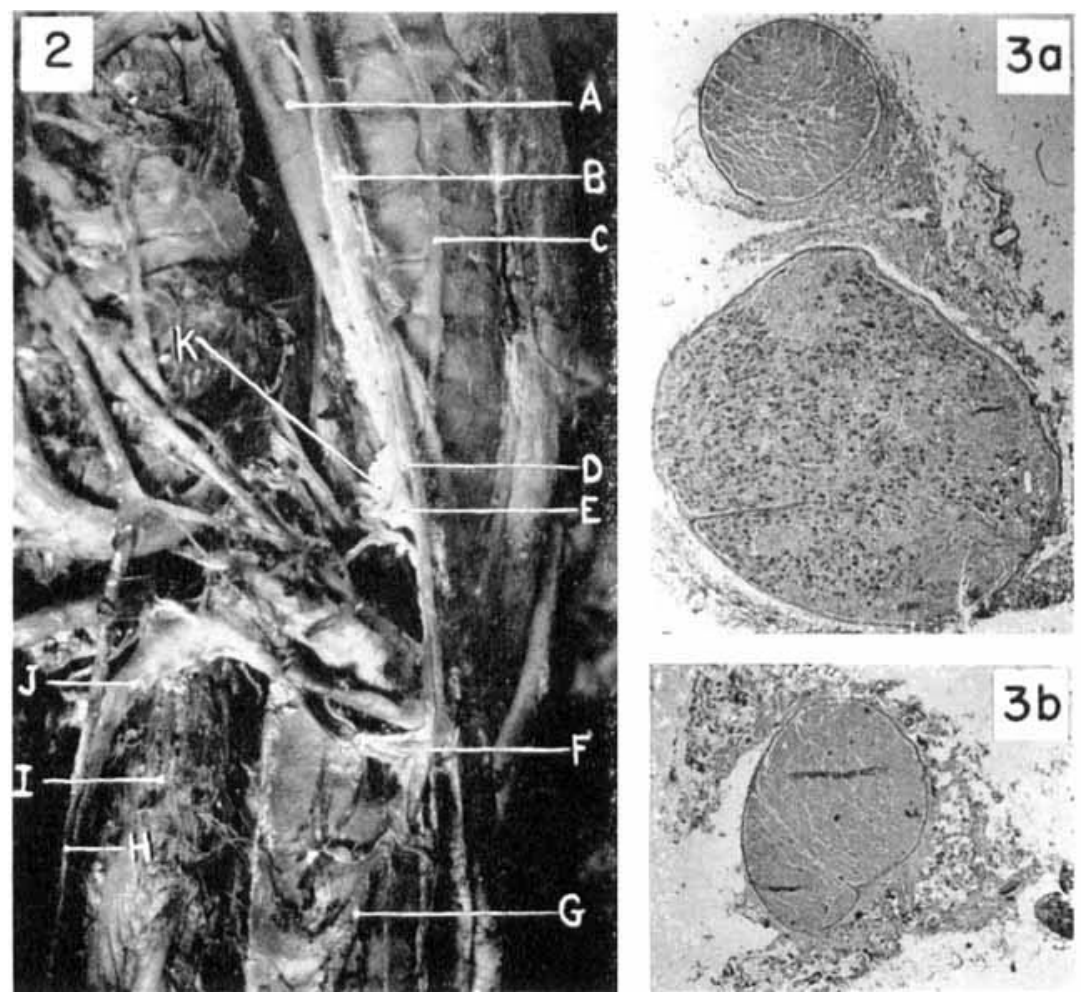

Fig. - A sheath dissection showing the separation of the ragus and sympathetic trunks. Right side. A. Common carotic artery. B. Vagosmpathetic trunk. (: Recurrent laryngeal nerve. D. Separation between vagus and sympathetic trunks. F. Caudal eervical ganglion. F. Ganglion on ventral limb of ansa subclavia. G. Vagus nerve. II. Phrenic nerve. T. Longus eolli muscle. J. Stellate ganglion. K. Epineurial shentl.

Fig. 3 a. Separation between the candal cervical ganglion and vagus nerve. The epinemial sheath has been partially dissected. Hematoxylin and eosin.

Fig. $3 \mathrm{~b}$ Beginning of fusion of the smaller sympathetie trunk and larger vagus nerve to form a vagosympathetie trunk. The common perineurial septum ean still be seen. Hematoxylin and eosin. 
of 6 cervical trunks were made and stained with hematoxylin and eosin. It is readily seen that in the middle cervical region a thin common perineurial septum (fig. $3 \mathrm{~b}$ ) still separates the two trunks (fig. 3 a). In the upper cervical region this common perineurial septum disappears so that both vagal and sympathetic fibers become intermingled. The vagosympathetic trunk sends branches to the trachea, esophagus, and common carotid artery.

\section{The thoracic region}

By incising the epineurial sheath, the extent, location, and variations of the vagal and sympathetic branches forming a cardiac nerve can be ascertained with comparative ease. This method of dissection has some application in nerve stimulation. If, in the living animal, the caudal cervical ganglion can be separated carefully from the vagus nerve with a needle or scalpel, it might be stimulated so that its specific effect on the heart could be determined. The same could be done with the vagus nerve and its branches. The following description is based on dissection of the sheath under a dissecting microscope. The figures are composite drawings and the nerves represented are those of most frequent occurrence.

Because of differences in number, course, and origin of cardiac nerves in dog and man, it is not possible to use identical terminology. Cephalad to the caudal cervical ganglion there is no cardiac nerve in the $\mathrm{dog}$, as was formerly maintained by Keng (1893), but later refuted by Nonidez ('39) and others. Thus, no superior (eranial) cardiosympathetic nerve can be identified in this form. Nonidez nevertheless named a superior cardiosympathetic nerve, since "in some instances it (superior cardiosympathetic nerve) may also carry bundles of fibers from the middle cervical ganglion to the deep cardiac plexus or to the anterior wall of the atria." Although such an arrangement was found in the majority of specimens in the present study, it does not seem a valid basis for the name ascribed to it. 
No superficial cardiac plexus, comparable to that in man, could be found in the dog. There is a plexus at the tracheal bifureation that may be compared to the deep cardiac plexus, but, as will be described, its components are not the same. Schurawlew ('27) regarded this plexus as the pretracheal plexus. He classified 6 epicardial plexuses as visualized by the methylene blue method. Actually, only three of these can be observed with the naked eye. These are his plexuses I and II (right and left coronary), and IV, which lies in the fold for the ligament of the left precaval vein in the dorsal wall of the left atrium and extends over the dorsal ventricular wall. Grossly, the primary areas of nerve distribution for the heart may be designated as pretracheal plexus, right and left coronary plexuses, dorsal ventricular plexus, and the fine plexus on the dorsal and ventral atrial walls.

1. The caudal cervical ganglion (figs. 4-7). The caudal cervical ganglion is about $3 \mathrm{~mm}$ in width and $5 \mathrm{~mm}$ in length. It lies lateral to, but in the same epineurium, with the vagal trunk on the medial aspect of the distal part of the subelavian artery, between the level of the first and second ribs. Its relation with the vagal trunk within the common epineurium may vary from complete separation to almost complete fusion (fig. 7). From the ventral surface of the caudal cervical ganglion arise one to three branches that contribute to the plexus on the beginning of the axillary artery (figs. 4-6) and supply surrounding lymph nodes (fig. 6) and common carotid artery (fig. 5). From the axillary plexus and the ganglion two or three filaments are sent to the 5th cervical nerve root of the phrenic nerve (fig. 6). The origin of these fibers in the dog is probably the caudal cervical ganglion. From the caudolateral pole of the ganglion arise the dorsal and ventral limbs of the ansa subclavia which connect to the stellate ganglion. Both limbs of the ansa contribute to the axillary plexus. Gray rami communicantes were found to the 7 th and 8 th and 6th cervical nerves, in only three specimens. If the cervical ganglia are named according to their ramal connection to the cervical nerves, the caudal eervical ganglion cannot 
be homologized with the middle cervical ganglion in man where it sends rami communicantes to the 5th and 6th cervical nerves (Larsell, 53). Since there is no inferior thyroid artery in the dog, and the ganglion is related to the origin of the vertebral artery, it is probably homologous to the human intermediate or vertebral ganglion, which usually sends rami communicantes to the 6th and sometimes 5th or 7 th cervical nerves, according to Kuntz ('45). Less confusion will arise by naming it the caudal cervical ganglion.

A filament from the dorsal surface of the left caudal cervical ganglion, along with a stem from the vagus, forms a mixed nerve coursing between the innominate and left subelavian arteries and reaching the base of the immominate artery and ventral surface of the aortic arch (fig. 4). According to Nonidez (39) this nerve carries one of the branches of the left depressor nerve. Since it does not reach the heart wall it camot be considered a cardiac nerve but may be referred to as the left innominate nerve (fig. 4). The right nervess to the large arterial walls were extremely variable in their origin. In 8 specimens, two separate nerve bundles entered the walls of the innominate. The rostral one (fig. 5) arose from the dorsal surface of the candal cervical ganglion in two specimens, and in 6 eases it arose by means of a stem that extends from the caudal cervical ganglion to the recurrent cardiac nerve (fig. 5). The caulal nerve (fig. 5), present in all specimens, arose by means of several stems from the right recurrent laryngeal nerve and the recurrent cardiac nerve. In 4 specimens both nerves were found to be multiple. The rostral nerve, according to Nonidez ('35, '37), carries the right depressor fibers. Both nerves may be designated as the right inmominate nerves (fig. 5). The other branches of the caudal cervical ganglion course in the cardiac nerves. Since they are mixed and difficult to homologize with the human, a different terminology is deemed necessary. All the cardiac nerves may be designated as eervical and stellate cardiac nerves. 
2. The ventromedial cervical cardiac nerve (fig. 4). The ventromedial cervieal cardiac nerve (Nonidez' leît superior eardiosympathetie) is formed from two stems, one from the dorsal surface of the caudal cervical ganglion and the other from the vagal trunk above the level of the ganglion. The nerve lies in the interval between the immominate artery and left vagus nerve. As it descends onto the ventral surface of the aortic arch it receives an additional vagal contribution and sends fibers to the aortic wall. It then proceeds toward the pulmonary bifurcation, medial to the ligamentum arteriosum, sending branches to the pulmonary arterial walls, pretracheal plexus, and pericardium. Another branch courses around and under the pulmonary bifurcation to reach the pretracheal plexus. The ventromedial cervical cardiac nerve was present in all the specimens but varied as to its origin and branches. In the majority of specimens it earried both vagal and sympathetic components which ramify over the aortic arch and pulmonary bifureation sending contributions, as a rule, to the pretracheal plexus. According to Nonidez ('39) the left branch of the left depressor nerve is carried by the rentromedial cervical cardiac nerve. He illustrated the left depressor nerve as a separate nerve lying between the ganglion and the vagal trunk. I failed to find this relationship in the adult dog.

3. The ventrolateral cervical cardiac nerve (fig. 4). The ventrolateral cervical cardiac nerve (Nonidez' left midulle cardiosympathetic) is the largest of all the cardiae nerves, approaching the size of the vagal trunk. It arises from the caudal pole of the caudal cervical ganglion, descends lateral to the vagus, and receives and gives anastomotic branchess to it. Just before reaching the ventral surface of the aortic arch, the nerve becomes plexiform. Before it reaches the ventral surface of the left pulmonary artery, filaments from the left recurrent laryngeal and stellate cardiac nerres (fig. 4) join it. Branches are also sent to the pericardium (fig. 4). On reaching the left dorsal atrial wall the plexus follows the vestigial fold of the left precaval vein, near the coronary 
sinus. After giving filaments to the atrial wall it proceeds to the dorsal ventricular wall where it sprearls out and may be ealled the dorsal ventricular plexus. According to Nonidez ('39) the ventrolateral cervical cardiac nerve contains, just below the ganglion, sympathetic postganglionic fibers together with a few afferents. The vagal and recurrent fibers that join it later probably enter the dorsal atrial wall, while the sympathetic postganglionic fibers enter the ventricular wall and the left pulmonary plexus.

4. The dorsal cervical cardiac nerve (fig. 4). The dorsal cervical cardiac nerve arises by means of one or more filaments from the dorsal surface of the caudal eervical ganglion and courses dorsal to the left subelavian artery or between the latter and the innominate artery. On reaching the dorsal surface of the aortic arch it sends filaments to the arch, descending aorta, and pretracheal plexus. In its course, it may be multiple or it may receive additional filaments from the ventral limb of the ansa subclavia, stellate ganglion, or vagal trunk. In three specimens it arose from the innominate nerve while in one specimen it was absent.

5. The recurrent cardiac nerve (figs. 4, 5, 7 ). The recurrent cardiac erve (Nonidez' right middle eardiosympathetic) is a large mixed nerve trunk arising from the right recurrent laryngeal nerve as it loops under the right subclavian artery. In 8 specimens it was found to receive a contribution from the caudal cervical ganglion, joining it near the loop of the right recurrent nerve. In 4 specimens this sympathetic contribution remained separate until it joined the recurrent eardiac nerve just before the latter entered the pretracheal plexus. In 7 specimens it also received a contribution from the ragal trunk near the origin of the recurrent nerve. As the nerve approaches the pretracheal plexus it receives an anastomotic branch from the left recurrent nerve (fig. 5) and sends a filament to the rostral nerve of the craniovagal nerves (fig. 5). After sending several filaments to the pretracheal plexus both dorsal and ventral to the right pulmonary artery, the main stem of the nerve, along with a few pretracheal con- 
tributions, breaks up into a right and left coronary plexus (figs. 4, 5). The recurrent cardiac nerve was present in all specimens dissected, but in 4 it ranged from a double strand to a plexiform arrangement. According to Nonidez ('39) it contains preganglionic, afferent, and a large number of sympathetic postganglionic fibers.

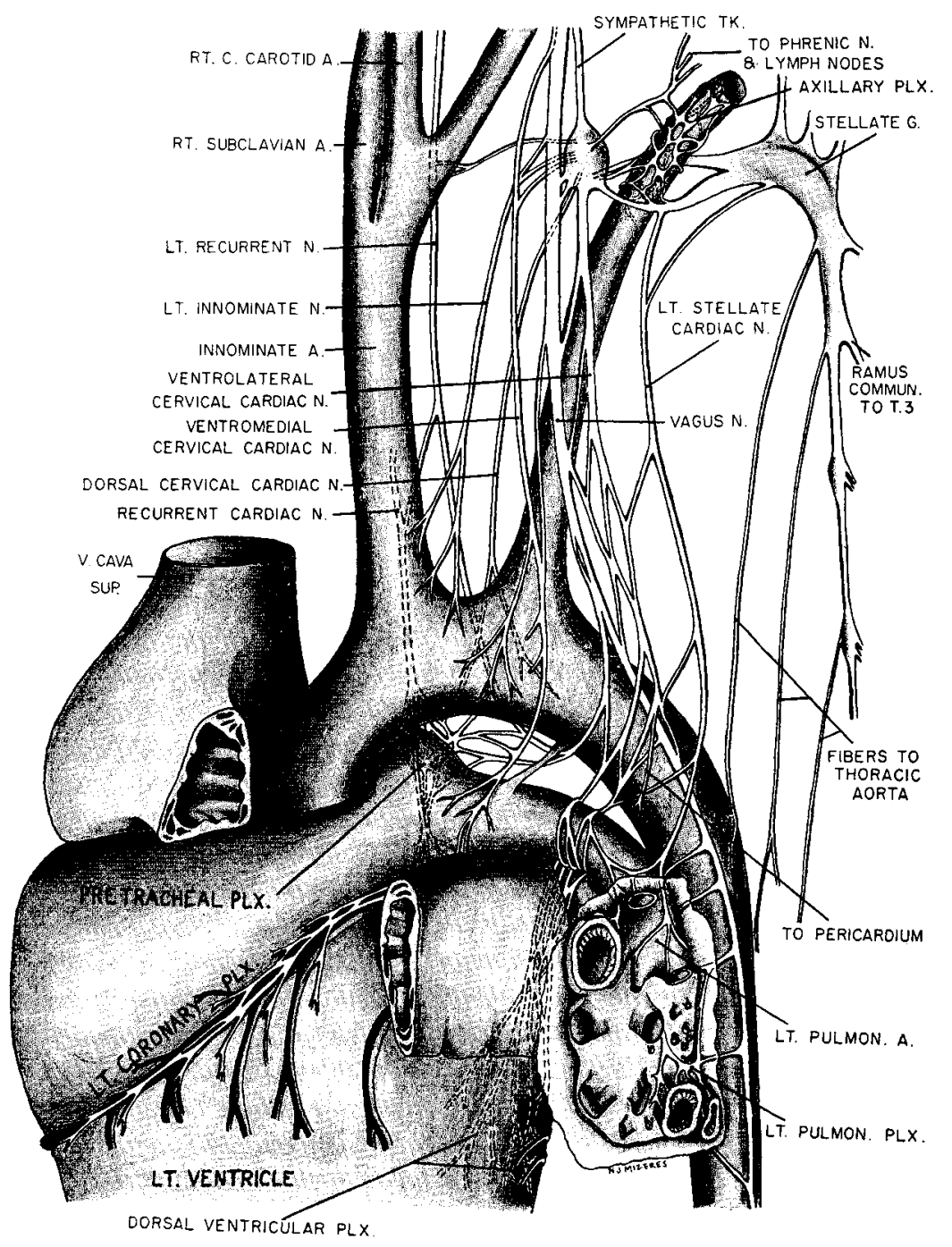

Fig. 4 Left side of the cardiac region. 
6. The ragal cardiac nerves (fig. 5). The vagal cardiac nerves arise from the right vagus nerve just below the ventral limb of the ansa subclavia. They may be grouped into two sets, the cranial and the caudal vagal cardiac nerves (fig. 5). All 4 nerves anastomosed with each other at the dorsal aspect of the precaval vein. The craniovagal nerves enter the pretracheal plexus, while the caudovagal nerves enter directly into the right dorsal atrial wall. Neither Nonidez ('39) $110 \mathrm{r}^{\circ}$ Schurawlew ('27) mentioned the caudovagal nerves. In 5 specimens the craniovagal cardiac nerves ranged from three separate strands to a plexus. The ragal cardiac nerves also sent filaments to the trachea.

\%. The stellate ganglion (figs. 4-7). The stellate ganglion is the largest of all the sympathetic ganglia in the dog. It lies on the dorsolateral aspect of the longus colli muscle extending between the first and third ribs. The thoracic duct lies medial to the ganglion. The rami communicantes of the ganglion are comparatively large and constant in the dog. The largest gray ramus extends from the cephalic pole of the ganglion, courses medial to the vertebral artery, and at the point where the vertebral artery enters its canal, the ramus runs over the artery, reaching the 7 th cervical nerve root (fig. 6). Here it fuses with the nerve to the longus colli muscle (fig. 6). It also contributes a branch to the plexus on the vertebral artery. The ramus communicans to the 8 th cervical nerve is variable. It may be single or double, passing cither side of the first rib (fig. 6). It may also arise in common with the ramus communicans to the first thoracic nerve. The mixed rami to T1 and T2 are short, whereas the ramus to T3 is much longer. Quite often, there is no visible ganglion in the svmpathetic trunk at the th thoracic level, so that the stellate ganglion may also contribute to the 4th thoracic nerve.

Van den Broek ('08) incompletely illustrated a vertelral nerve in the dog. It (fig. 6) arises from the cephalic pole of the stellate ganglion, either as a separate nerve or fused with the ramus to the 7 th cervical nerve, and follows the merlial surface of the rertebral artery into its canal where the nerve 
joins the vertebral plexus. Quite often a separate branch from the ramus to the 7 th eervical nerve entered this plexus.

The ansa subclavia (figs. 4,6) is formed by the splitting of the sympathetic trunk by the subclavian artery between the caudal cervical and the stellate ganglia. Its ventral and dorsal

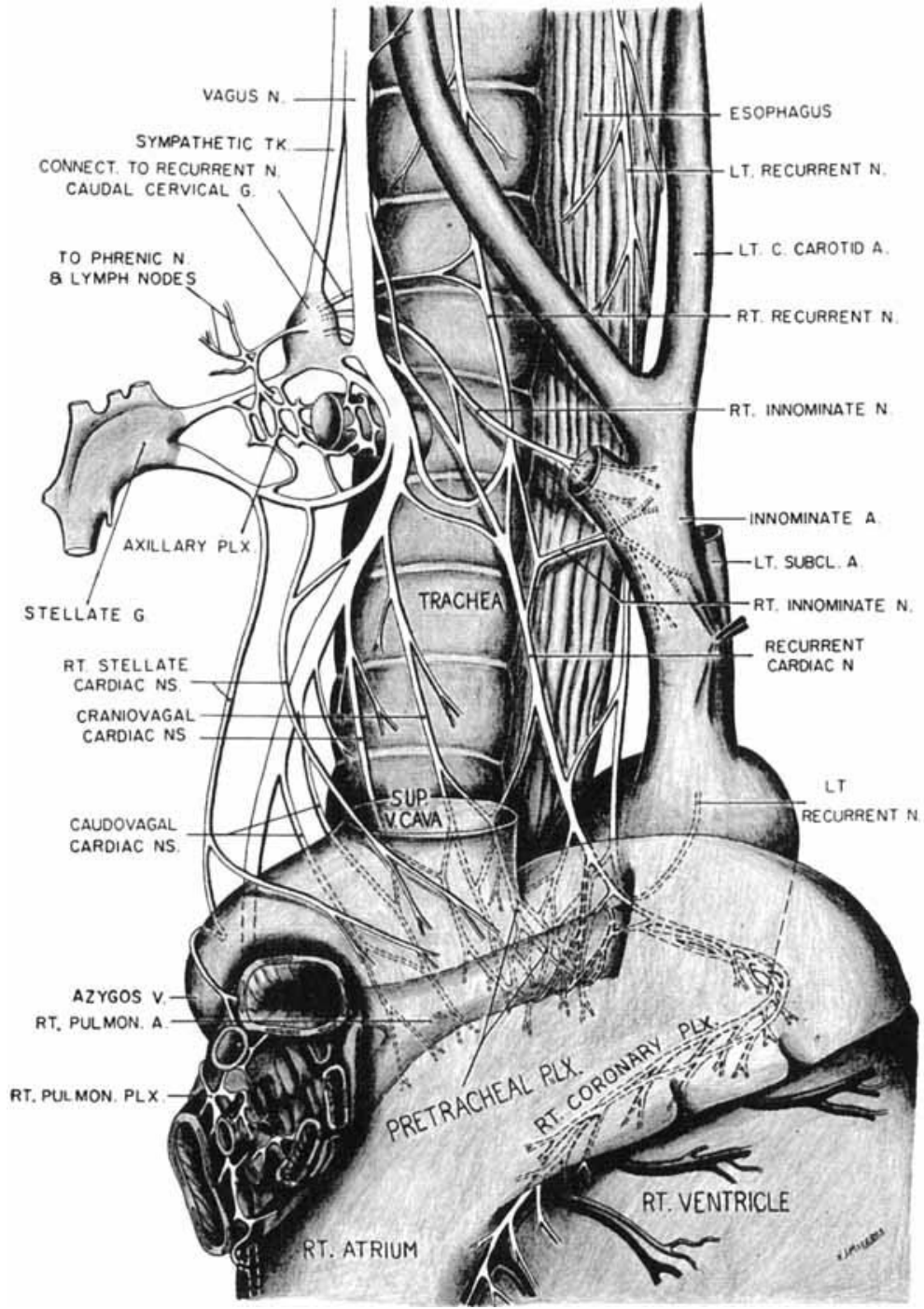

Fig. 5 Right sille of the cardiac region. 
limbs may again be split. Nonidez ('39) described ganglionic aggregations in the ventral limbs of the ansa in histological preparations. By dissecting away the sheath a ganglion of observable size was found in three of my specimens (fig. 2). Both limbs of the ansa contribute to the axillary plexus. The right ansa subclavia differs from the left since its ventral limb may connect directly to the stellate ganglion (fig. $7 \mathrm{~A}$ ), or it may run within the sheath of the vagus nerve (fig. $7 \mathrm{C}$ ). Other variations were also found (fig. 7).

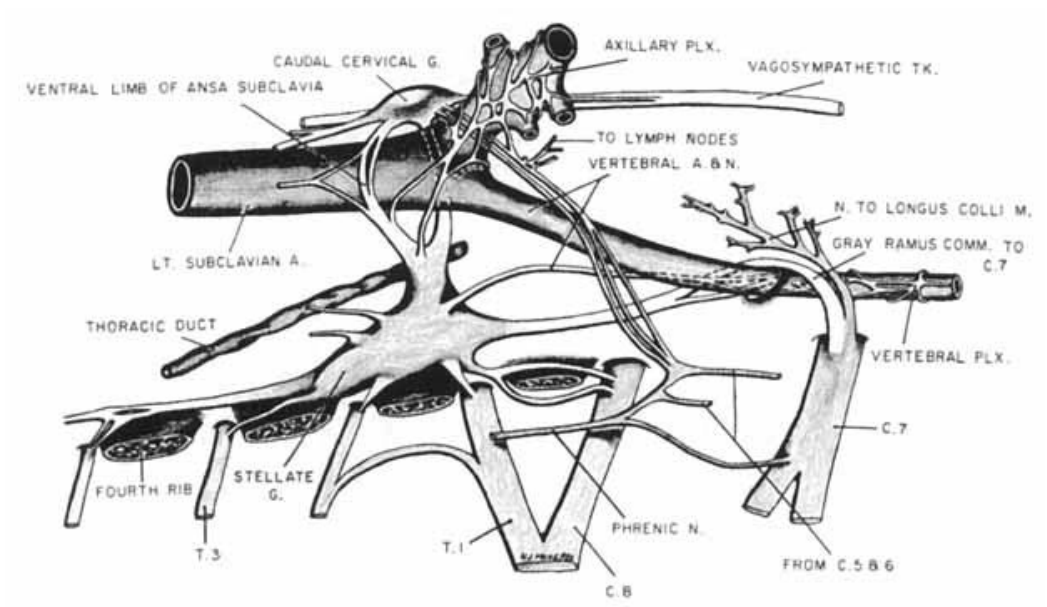

Fig. 6 Left side. The stellate and caudal cervieal ganglia.

8. The stellate cardiac nerves. The left stellate cardiac nerve (fig. 4) is variable, ranging from a comparatively thick nerve to a fine plexus, and in 5 specimens it was absent. In 4 specimens it arose from the stellate ganglion and in one it arose from the ventral limb of the ansa subclavia. It sent filaments to the left pulmonary plexus, ventrolateral cervical cardiac nerve, and to the dorsal ventricular plexus. The right stellate cardiac nerves (figs. 5, 7) (Nonidez' right inferior cardiosympathetic nerve) arose (ither from the stellate ganglion, from both the ganglion and ansa subclavia, or from the ganglion, ausa subelavia and vagal trunk. Their number ranged from one to 5 norves, either fused or separate. They 
course over the ventral surface of the base of the precaval and azygos veins, contributing to the right pulmonary plexus and the right dorsal and ventral atrial walls. Nonidez ('39) found no distinct nerve from the right stellate ganglion, but mentioned the possibility that postganglionic fibers might course within the ventral limb of the ansa and join those from the caudal cervical ganglion ('39). In 5 cases only one or' two filaments were present, and in one three large nerves arose directly from the caudal cervical ganglion with contributions from the ventral limb of the ansa subclavia and vagus nerve (fig. $7 \mathrm{~A}$ ). These nerves entered the right atrial walls and pulmonary plexus, thus indieating that in the one specimen the stellate cardiae nerves may course through the caudal cervical ganglion and only appear as branches of the ganglion. It is also probable that when the stellate cardiac nerves appear as only one or two filaments, the rest of the nerves may course as postganglionic fibers through the caudal cervical ganglion and in the sheaths of the vagal cardiac nerves (fig. $7 \mathrm{D})$.

9. Cardiac nerves below the stellate ganglion. Ionescu, Schurawlew, Nonidez and others described cardiac nerves arising below the stellate ganglion in both man and dog. Although there is agreement about man, evidence is conflicting concerning the dog. Ionescu ('28) found no branches in one dog, a few on the right side in two, and a few on both sides in one. Schurawlew ('27) illustrated branches from T'2 and T3 on the left side only. These nerves were looked for with great care in all the specimens dissected in this study. In only two cases one or two filaments were found entering the puimonary plexus, but none passed to the heart wall. Definite filaments to the descending and thoracic aorta were found arising constantly from all the ganglia or interganglionic rami of the thoracic sympathetic trunk down to T12. In many cases these filaments (fig. 4) were interconnected in a plexiform manner with an oceasional ganglion near the wall of the aorta. 
10. The plexuses of the thoracic region. The axillary plexus (figs. 4-6) is formed by filaments arising from both limbs of the ansa subclavia, the caudal cervical ganglion, and variably from the stellate ganglion. It lies on the axillary

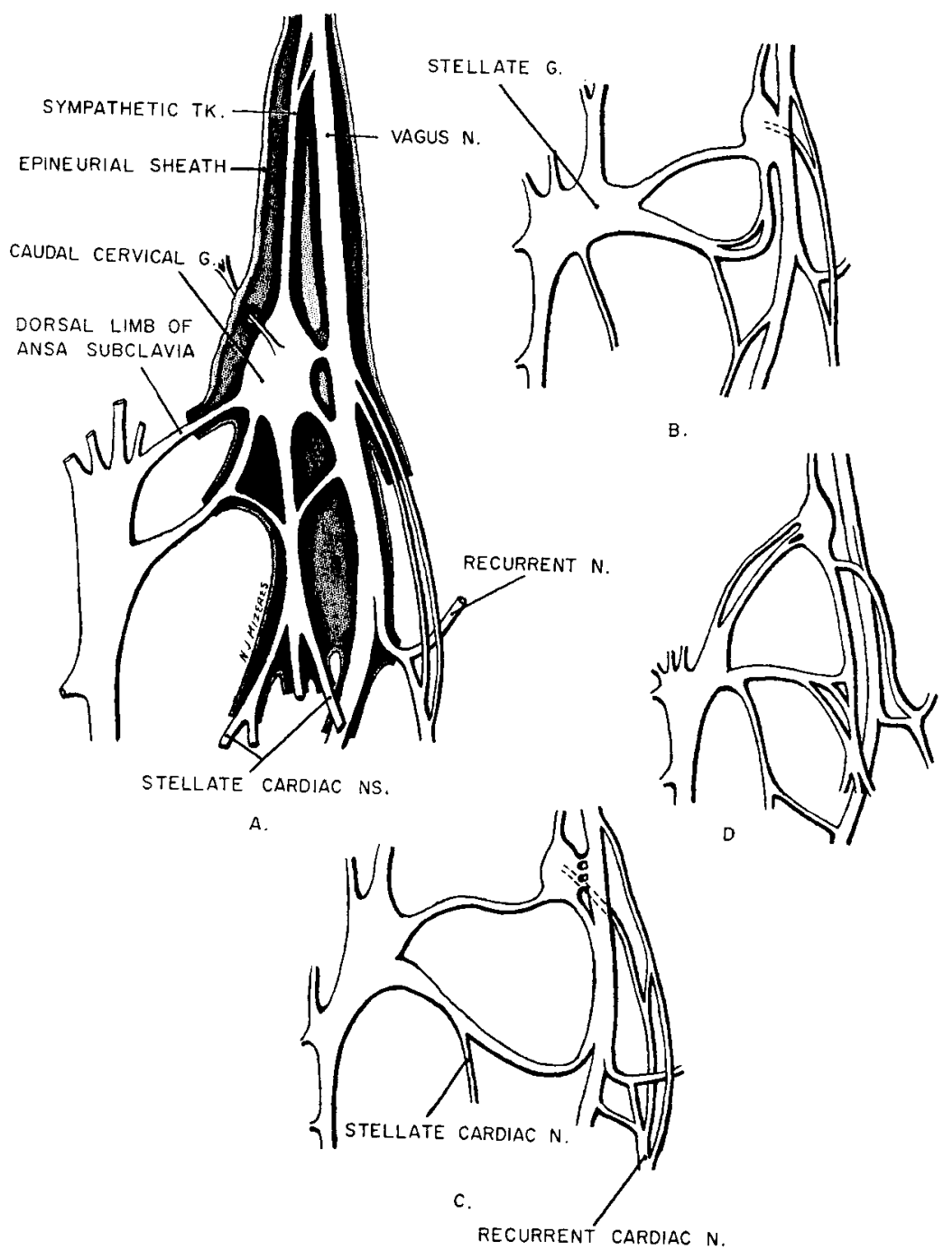

Fig. 7 Right side. Variations of the caudal cervical and stellate ganglia, ansa subclavia and carcliac nerves. In $A$, the epineurial sheath is shown in relation to the nerves. 
artery and sends subordinate plexuses to its branches. The axillary plexus is also comnected with the 5 th cervical root of the phrenic nerve (fig. 6). The vertebral plexus (fig. 6) lies on the vertebral artery as it enters its canal. It is formed by the vertebral nerve (fig. 6 ) and by variable filaments from the gray ramus communicans to the 7 th cervical nerve (fig. 6). It may send gray rami communicantes to the upper cervical nerves emerging through the intervertebral foramina, but I could not definitely ascertain this by gross dissection. The right pulmonary plexus (fig. 5) is formed by vagal branches and filaments from the stellate cardiac nerves. The caudal portion of the plexus is formed by direct branches of the right vagus nerve. The left pulmonary plexus (fig. 4) is formed by filaments from the dorsal ventricular plexus, as it coursed over the left pulmonary artery, and from branches of the left vagus and stellate cardiac nerves. The caudal portion of the plexus is formed directly by the left vagus nerve. The pretracheal plexus (figs. 4, 5) lies ventral to the tracheal bifurcation and dorsal to the right pulmonary artery. Some of its branches also ran ventral to the artery (fig. 5). It receives filaments from the left recurrent, ventromedial cervical cardiac nerve, the recurrent eardiac nerve, the dorsal cervical cardiac nerve, and the craniovagal cardiac nerves. The plexus sends filaments to the dorsal atrial walls and to the right and left coronary plexuses. The coronary plexuses (figs. 4, 5) are extensions of the pretracheal plexus. The principal contribution comes from the recurrent cardiac nerve (fig. 5), whose major stem seems to form the plexuses directly. Filaments from both plexuses also enter the root of the ascending aorta (fig. 5). The main trunks of the plexuses follow the course of the right and left coronary arteries into the ventricular wall. The dorsal ventricular plexus (fig. 4) begins as a network of filaments on the ventral surface of the left pulmonary artery and vein coursing over the left dorsal atrial wall in relation to the coronary sinus, and finally entering and spreading out on the left dorsal ventricular wall. It is derived mainly from the ventrolateral envical cardiac 
nerve with minor additions from the left recurrent laryngeal nerve, as that nerve courses under the ligamentum ateriosum, and from the left stellate cardiac nerve.

11. The thoracic vagus and sympathetic trunk. The dog having 13 ribs, 13 levels are to be considered. The sympathetic trunk is constant in its ramal connections to the spinal nerves, but the observable ganglia are not. The ganglia begin at the 4th thoracic level and continue to the 9th thoracic level. From the 9 th to the 13 th thoracic level the trunk appears as a single strand. In all the specimens branches reach the aorta from the ganglia or interganglionic rami of the left trunk. These branches are interconnected in a plexiform manner and in 4 specimens minute ganglia were present among the branches. On the right the branches are fewer and ramify on the wall of the azygos vein and esophagus.

Both vagi course dorsal to the pulmonary roots, send branches to the esophagus, and each immediately divides into a ventral and a dorsolateral branch. The right ventral branch is longer than the left. In 4 specimens the shorter left branch was double. A fusion of both ventral branches oceurred in the upper third of the esophagus in three specimens and in 7 specimens the fusion occurred in the middle third of the esophagus. This ventral fusion forms the ventral gastric nerve (fig. 8), which courses on the ventral surface of the esophagus and enters the abdomen through the esophageal hiatus. The dorsolateral branch of both vagi courses at first lateral to the esophagus and then dorsal in the lower third of the esophagus. Fusion of these dorsal branches to form the dorsal gastric nerve (fig. 8) occurs in the lower third of the esophagus, so that the dorsal gastric nerve is much shorter than the ventral nerve. Dircet branches from both dorsal and ventral branches of the vagus nerves enter the esophagus. Dowgiallo ('28) described an esophageal plexus in the dog. Like Hilsabeck and Hill ('50), I conld not demonstrate this plexus. 


\section{The abdominal region}

1. The vagus nerve. The right and left vagi enter the abdominal eavity as the dorsal and ventral gastric nerves. The ventral gastric nerve, after passing the esophageal hiatus, breaks up into a short plexus. From this plexus two groups of branches arise, a hepatic and a gastric group. The hepatic branches, two or three in number, leave this short plexus and course through that part of the lesser omentum near the cardiac region of the stomach mingling with the filaments lying on the interlobar branches of the hepatic artery (fig. 8). The gastric branches, three or 4 in number, supply the ventral surface of the stomach. The largest stem of the gastric branches follows the lesser curvature, sending branches to the pyloric portion and ending near the pyloric sphincter. A number of filaments arise from the ventral gastric branches and anastomose with the sympathetic plexus on the branches of the left gastric artery (fig. 8). The dorsal gastric nerve (fig. 8), shorter than the ventral, follows the dorsal surface of the cardiac region of the stomach. After sending a few branches to this area it breaks up into a plexus through which the esophageal arteries (fig. 8) course. The branches of the plexus anastomose with the plexus on the celiac and proximal portion of the left gastric arteries (fig. 8). In 5 specimens separate dorsal gastric branches from this plexus were followed to the hepatic and cranial mesenteric plexuses. The main stem of the plexus follows the lesser curvature, sending branches to this area and to the dorsal surface of the pyloric portion of the stomach where the nerve disappears into its wall. In 5 specimens, I found the dorsal gastric nerve sending several hepatic filaments (fig. 8) through the gastrophrenic ligament to the plexus on the terminal branches of the hepatic artery. Neither Hilsabeck and Hill ('50) nor McCrea and D'Arcy ('25) mentioned these hepatic branches.

2. The abdominal plexuses and collateral ganglia. The celiacomesenteric plexus surrounds the roots of the celiac and eranial mesenteric arteries. Due to its density it forms 


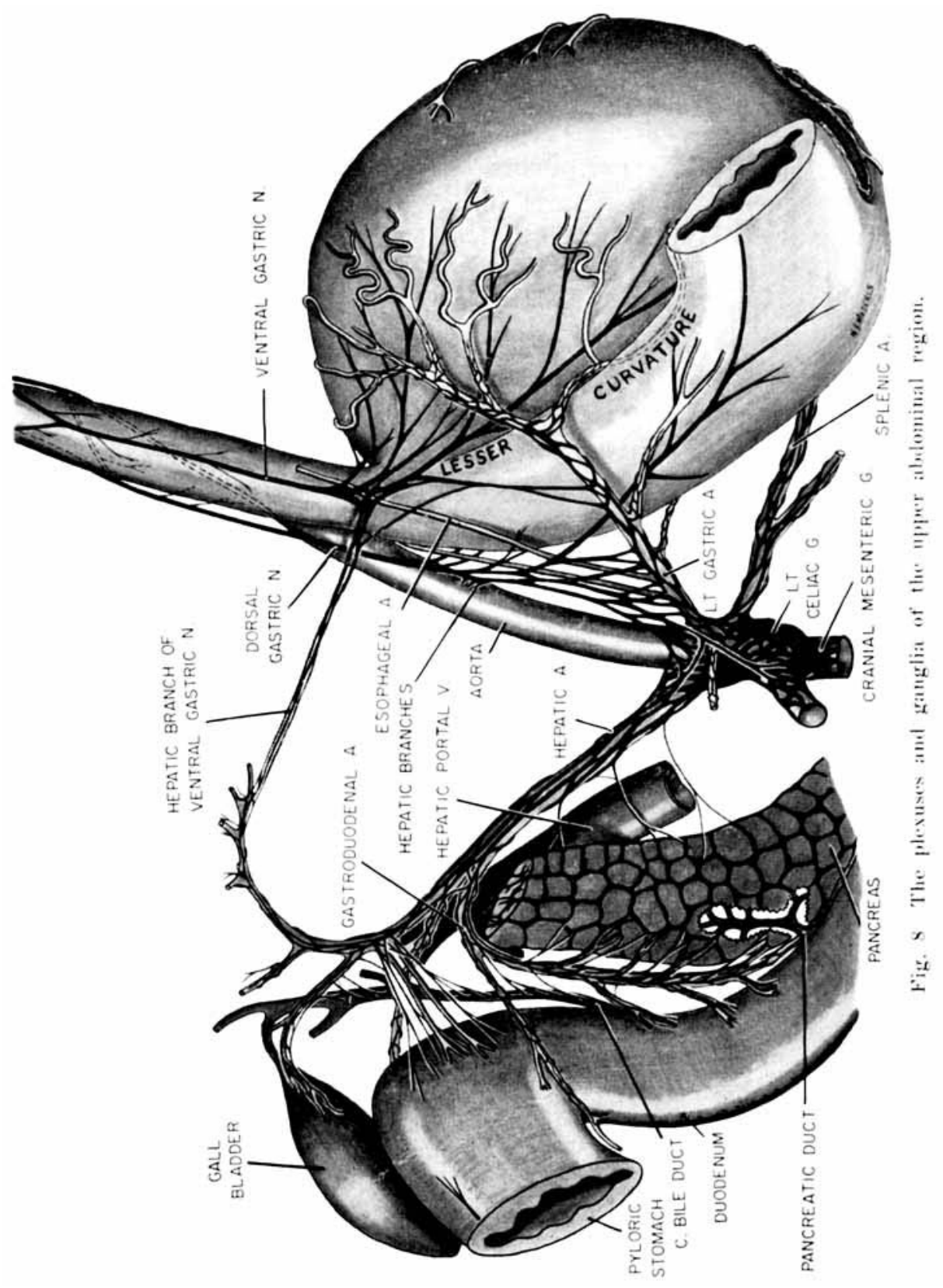


a tight ring around both arterial stems. It sends subordinate plexuses along the branches of the celiac and cranial mesenteric arteries, which are named according to the branches on which they lie. The celiac (figs. 8-9) and single cranial mesenteric (figs. 8-9) ganglia lie in the meshes of the plexus. Although both celiac ganglia receive filaments from the dorsal gastric nerve the right ganglion receives more direct branches (fig. 8). The plexus on the hepatic artery (figs. 8-9) is dense and often completely covers its adventitial surface. It is formed mainly by the right celiac ganglion and dorsal gastric nerve. The plexus also sends branches that course ventral to the portal vein (fig. 8) and enter the pancreas. From that part of the hepatic plexus that lies near the origin of the pyloric arteries direct branches are sent to the common bile duct and pyloric portion of the stomach (fig. 8). The plexus on the gastroduodenal artery sends filaments to the duodenum, pancreas, and terminal portion of the common bile duct (fig. 8). The right gastric and gastroepiploic plexuses supply the right portion of the greater and lesser curvatures of the stomach. The plexus on the cystic artery supplies the cystic duct, gall bladder, and proximal part of the common bile duct. The terminal branches of the hepatic artery carry the terminations of the hepatic plexus and, if dissected with eare, these terminal filaments may be seen to enter the liver lobes through the interlobar arteries and to anastomose with the hepatic branches of the ventral gastric nerve (fig. 8). The splenie plexus (figs. 8-9) follows the artery and sends branches to the spleen, body, and tail of the pancreas, and to the left portion of the greater curvature of the stomach by way of the left gastroepiploic artery. It is formed mainly by the left celiac ganglion. Direct pancreatic arteries from the celiac artery also carry filaments to the pancreas (fig. 8). The left gastric plexus (figs. 8-9) on the left gastric artery enters the left portion of the lesser curvature, fundic, and cardiac areas of the stomach. Near the cardiac area, the filaments on the arteries anastomose with the branches of the ventral gastric nerve (fig. 8). This plexus is formed by both celiac 
ganglia and the dorsal gastric nerve. The bilateral phrenic plexus (fig. 9) was found to arise by direct branches from the celiac ganglion. After entering the upper portion of the muscular crura, the plexus was observed to connect with the phrenic nerve (fig. 9). Although a phrenic ganglion is described by Larsell ('53) in man, no ganglion was observed in this area in the dog. In one specimen a separated "phrenic" ganglion from the left celiac ganglion occurred along the phrenic artery. The bilateral adrenal plexus (fig. 9 ) is a dense network of filaments that is completely covered by the adrenal gland. Within the meshes of the plexus, besides many arteries, minute adrenal ganglia are found. These ganglia lie along branches running from the celiac ganglia into the adrenal gland. The rest of the plexus is formed from the celiac and splanchnic (fig. 9) ganglia and from direct branches arising from the thoracic splanchnic nerve near the splanchnic ganglion. The renal plexus (fig. 9) is formed from branches arising either from the splanchnic and aorticorenal ganglia or from the aorticorenal ganglia only. Among its bundles one or two renal ganglia (fig. 9) were found in all my specimens. The dense plexus descends to reach the wall of the renal artery as it enters the renal sinus. The unpaired cranial mesenteric plexus (figs. 8,9) is formed by the cranial mesenteric ganglion with contributions from both celiac ganglia. Branches of the dorsal gastric nerve were also observed to enter the plexus directly (figs. 8,9). Branches of the plexus followed the branches of the cranial mesenteric artery to the small intestine and part of the large intestine. According to Schmidt ('33), in the dog, the vagal fibers are distributed at least as far as the distal portion of the transverse colon.

The unpaired intermesenteric (aortic) plexus (fig. 9) is a group of long parallel bundles lying on the ventral surface of the aorta connecting the cranial and caudal mesenteric ganglia. In 8 out of the 10 specimens, one of these bundles became greatly thickened several centimeters below the cranial mesenteric ganglion, and extended caudally to connect with the caudal mesenteric ganglion. Trumble ('34) and 
Learmonth and Markowitz ('29) designated this thickened bundle as the "celiac root" of the inferior (caudal) mesenteric ganglion. The term is not a valid one since this thick bundle has no connection with the celiac ganglion and the term "root" is misleading. It is only a thickened part of the intermesenteric plexus, since in all my specimens at least two or three thinner strands were associated with it. It was found to vary in position and fine filaments from the plexus were observed entering the adventitia of the abdominal aorta (fig. 9).

The internal gonadal plexuses (fig. 9) may be grouped into two sets, a proper and an acessory group. The proper plexus, associated with the internal gonadal artery, was present in all the specimens. A gonadal ganglion (fig. 9) associated with the proper plexus was observed in three specimens on the left side and in one specimen on the right side. In another specimen a ganglion was observed near the hilum of the ovary. The accessory gonadal plexus, associated with an accessory internal gonadal artery (fig. 9) was found in 5 specimens. But in three specimens, although the artery was absent, this accessory plexus took origin from the aortic plexus at the same level and, associated with a ganglion, descended and came into relation with the proper left internal gonadal artery which had a higher origin than usual. Thus the accessory plexus was observed in 8 specimens. An accessory gonadal ganglion (fig. 9) was associated with this plexus in three of the 4 females and 5 of the 6 males.

The plexus on the caudal mesenteric artery consists of two or three thick strands which follow the branches of the artery and form a dense meshwork that can be followed cranially to the branches of the cranial mesenteric artery. Caudally, this plexus was followed on the hemorrhoidal vessels and some of its filaments were observed to anastomose with dorsal filaments of the hemorrhoidal part of the pelvic plexus (fig. 10). Learmonth and Markowitz ('29) mentioned "lumbar" colonic" nerves which apparently run independently of the caudal mesenteric plexus. No specific mammal was mentioned 
in their work and I could not find these nerves in any of my specimens.

3 The thoracic splanchnic nerve. In none of the specimens did I observe nerves comparable to the human lesser and least splanchnic nerves. There was only one large ahdominal sympathetic nerve that emerged from the thoracic sympathetic trunk. It may be designated as the thoracie splanchnic nerve (fig. 9). It is larger than the trunk itself and courses under the medial lumbocostal arch and lateral to the crus of the diaphragm. The nerve sends filaments to the thoracic aorta before passing the margins of the lumbocostal arches (fig. 9). Just before joining the splanchnic ganglion (fig. 9), the thoracic splanchnic nerve sends direct filaments to the adrenal gland. The level of emergence from the thoracic sympathetic trunk occured in 7 specimens from th: 13 th thoracic ganglion and in three specimens from the trunk between the 13th thoracic and first lumbar levels. In 7 specimens the thoracic splanchnic nerve was comneted to the first lumbar splanchnic nerve by a variable number of fine filaments. In 4 specimens it also received a short contribution from the sympathetic trunk at the first lumbar level.

4. The lumbar sympathetic trunk and its branches. The lumbar sympathetic trunk and its variations have been earefully studied by Mehler, Fischer and Alexander (52). The lumbar trunk begins as a thin strand arising from the first lumbar ganglion and courses under the medial lumbocostal arch, lateral to the erura and medial to the psoas muscles. The trunk and ganglia become thicker and longer caudally. There are 7 lumbar vertebrae in the dog. Mehler ('52) stated that out of 100 dogs only $37 \%$ showed a ganglion at each lumbar level. In 6 of my specimens fusion occurred between the first and second lumbar ganglia, unilaterally or bilaterally, with occasional fusion in other parts of the trunk (fig. 9). According to Melnler ( 52 ) the lowest preganglionic outflow of the sympathetic trunk occurred at the 4 th lumbar level in $65 \%$ of his specimens and at the 5th or 6th lumbar level in the remaining $35 \%$. Caudally the lumbar sympathatic trunks 
fuse in a variable fashion. According to Mehler ('52) fusion most often occurred at the 7 th lumbar lerel. This was true in 6 of my specimens.

From the first through the 5th lumbar level definite visceral branches of the sympathetic trunk have been found in all 10 specimens. The first lumbar splanchnic nerve (fig. 9) arises from the first lumbar ganglion or trunk. In 8 specimens it was found comnected to the thoracic splanchnic nerve by means of several fine filaments. The nerve, which may be split, courses under the lumbocostal arches, over the crura of the diaphragm and above the renal artery, and usually enters the aorticorenal and cranial mesenteric ganglia, including the intermesenteric plexus. The second lumbar splanchnic nerve (fig. 9) arises from the sympathetic trunk or ganglion at the second lumbar level and courses dorsal to the renal artery and emerges on its ventral surface and sends filaments to the intermesenteric plexus or to the cranial mesenteric ganglion. It usually sends a filament to the accessory gonadal ganglion if there is one. In three cases it sent branches to the renal plexus, and in two others it sent filaments to the aorticorenal ganglion. The third lumbar splanchnic nerve (fig. 9) arises from the third lumbar ganglion or sympathetic trunk, and courses toward the ventral surface of the abdominal aorta caudal to the renal artery. It divides into sereral filaments just before reaching the upper portion of the intermesenteric plexus. In two specimens it was found to be double, in which case filaments were also sent to the second lumbar splanchnic nerve, and from one of these nerves filaments were found entering the left aorticorenal ganglion and renal plexus. In two specimens filaments were seen entering the accessory gonadal ganglion and in two cases filaments enttered a proper ovarian ganglion. In another two cases, unilateral branches from the third lumbar splanchnic nerve were observed entering the cranial mesenterie ganglion. The 4th lumbar splanchnic nerve (fig. 9) arises from the 4th lumbar ganglion or level of the trunk and descends just above the proper gonadal artery to enter the intermesenteric and 


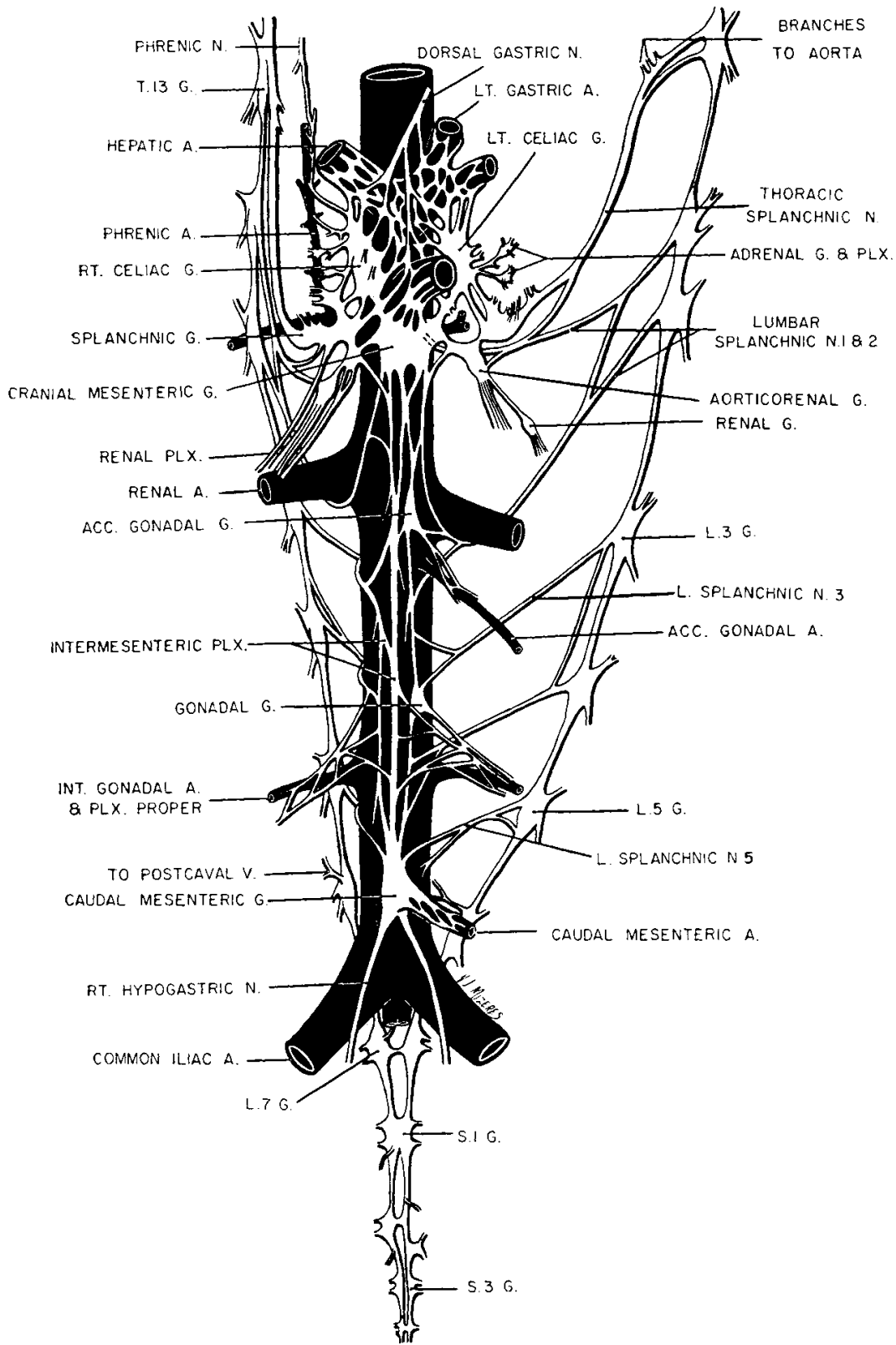

Fig. 9 The lumbosacral sympathetic trunk, its branches, and the collateral ganglia. 
proper gonadal plexuses. This pattern was constant in all 10 specimens. The 5th lumbar splanchnic nerve (fig. 9) arises from the 5th lumbar ganglion and courses just below the proper gonadal artery to enter the caudal mesenteric ganglion directly. In only one case was this nerve absent. Although filaments from the 6 th and 7 th lumbar levels were variable, when present, these splanchnic branches always entered the caudal mesenteric ganglion. In two cases, a ganglion was observed on the course of the 7th lumbar splanchnic nerve. In another two specimens a ramus arising from a left 7 th lumbar nerve followed the right hypogastric nerve to the pelvic plexus. These variable splanchnic nerves, along with direct fibers from the 6 th and 7 th lumbar ganglia, sent filaments to the postcaval vein (fig. 9) and iliac arteries.

\section{The pelvic region}

1. The hypogastric nerves (figs. 9-11). The hypogastric nerves of the dog arise from the caudal pole of the caudal mesenteric ganglion. The two nerves course retroperitoneally over the common iliac arteries and over the promontory of the sacrum to enter the pelvis. After reaching the lateral surface of the rectum they anastomose with the pelvic nerves (fig. 10) to form a dense pelvic plexus (fig. 10) lying under the pelvic peritoneum as it is reflected over the upper part of the rectum. In 8 specimens fine filaments were observed connecting both hypogastric nerves and the caudal mesenteric plexus (fig. 10). Only a few filaments from the hypogastric nerves to the iliac vessels were observed.

2. The pelvic nerves (figs. 10-11). The pelvic nerve arises by one or two stems from the first, second, and third sacral spinal nerves. It courses under the parietal peritoneum deep in the floor of the pelvis. After reaching the lateral wall of the lower rectum it anastomoses with the descending hypogastric nerve. From this anastomosis the dense pelvic plexus takes origin and sends branches to the pelvic viscera. In three specimens the pelvic nerve appeared double unilaterally. 
3. The pelvic plexus (figs. 10-11). The pelvic plexus is a dense network of filaments arising from the fusion of the hypogastric and pelvic nerves. It lies near the lateral surface of the rectum and is intermingled with the branches of the urogenital artery (fig. 10). Within its meshes are found a variable number of ganglia. The sublivisions of the pelvic

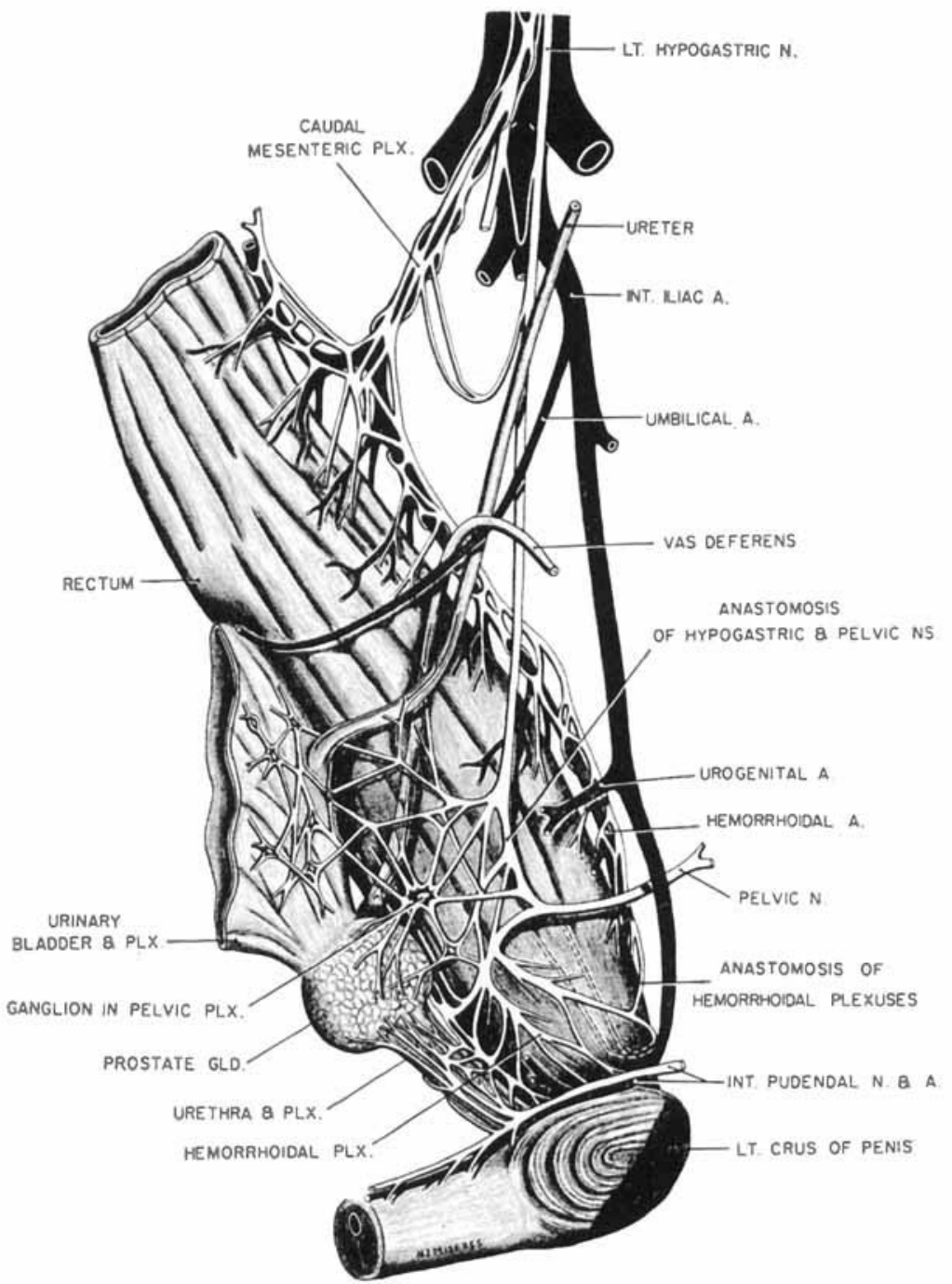

Fig. 10 The pelvic and caudal mesenteric plexuses in the male. I,eft side. 
plexus are named according to the organ innervated, such as, prostatic, vaginal, urethral, and hemorrhoidal plexuses. The urinary bladder and its intrinsic and extrinsic plexuses were carefully studied by Schabadasch ('26). The extrinsic plexus is readily seen as a fine network with small ganglia concen-

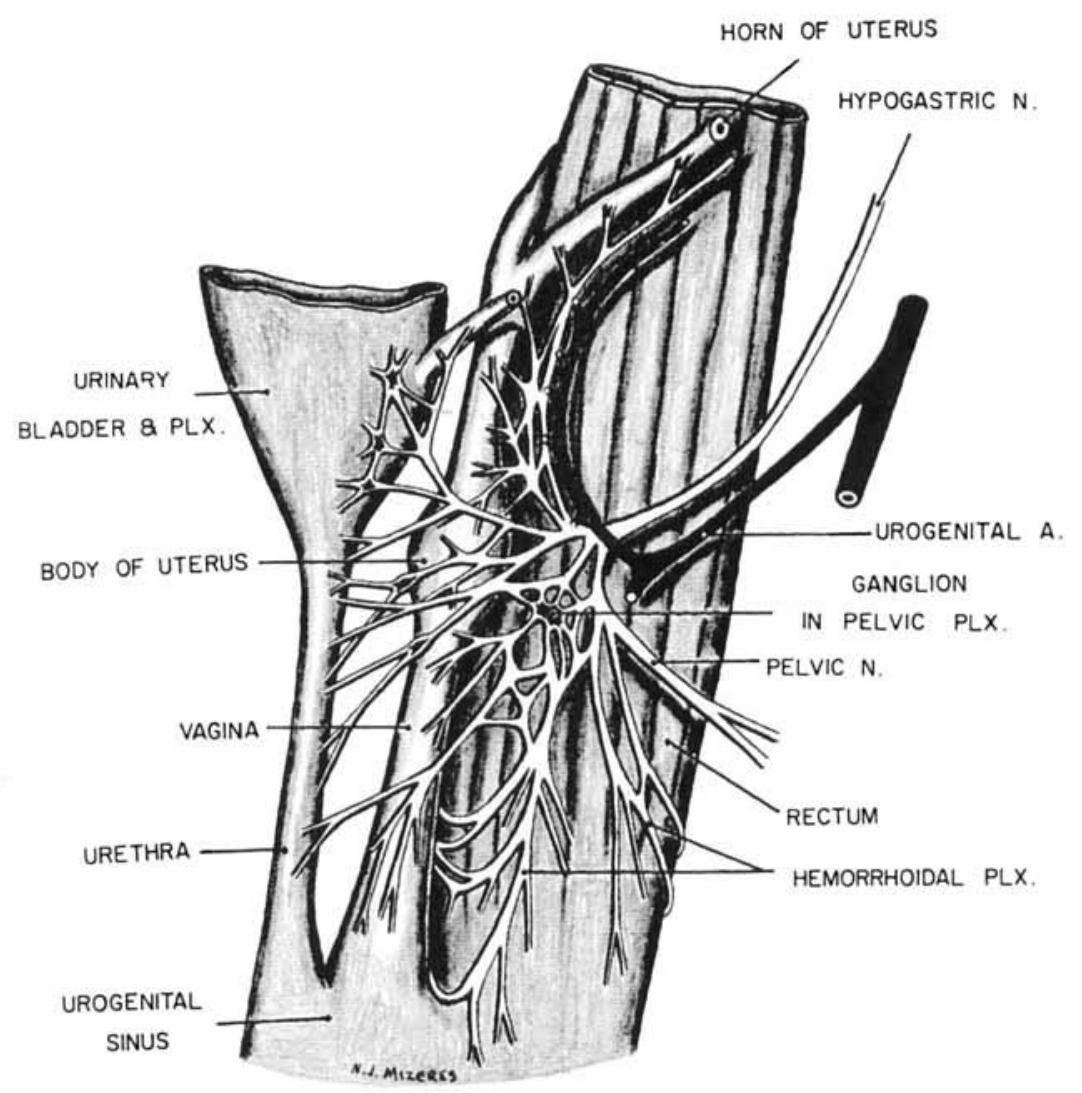

Fig. 11 The pelvie plexus in the female. Left silte.

trated near the neck of the urinary bladder. The female urogenital plexus was described as subdivided into vaginal and uterine plexuses by Medowar ('27). Although the pelvic organs innervated by the pelvic plexus are different in the male and female, the plexus itself was found to be the same. 
All the pelvic organs receive a rich nerve supply. The plexus on the male urethra anastomoses with filaments from the internal pudendal nerve (fig. 10). The hemorrhoidal plexus sends ascending branches into the dorsal rectal wall and anastomotic filaments over the ventral surface of the rectum to reach the opposite pelvic plexus. It also sends a few filaments which anastomosed with the sympathetic plexus on the hemorrhoidal vessels (fig. 10). Mitchell ('35) and Telford and Stopford ('34) described in man the path of the sacral parasympathetics as coursing through the mesocolon at right angles to the branches of the inferior mesenteric artery. This relationship was not found in any of the $10 \mathrm{dogs}$. In the dog the sacral parasympathetics appeared to ascend in the muscular wall of the rectum and also within the sympathetic plexus of the hemorrhoidal vessels.

4. The sacral sympathetic trunk (fig. 9). As mentioned previously the 7th lumbar ganglia are either fused or connected by a number of short filaments so that the sacral sympathetic trunks lie close together. In conjunction with this close relationship I found some form of horizontal fusion between the sacral ganglia. Although the ganglia were extremely variable, gray rami communicantes were found to enter all the sacral spinal nerves. Fine filaments were also observed ramifying on the middle sacral artery. A "ganglion impar" mentioned by Mehler ('52) and Miller ('49) could not be found in any of my specimens. The sympathetic trunks were observed to extend into the tail region.

\section{SUMMARY AND CONCLUSIONS}

The gross anatomy of the autonomic nervous system of the dog, excluding the cephalic region, is described and illustrated on the basis of 10 complete dissections. The following findings warrant emphasis :

1. The cranial cervical ganglion sends branches to the common carotid artery and its terminal branches, including the thyroid artery. It also sends separate filaments to the thyroid gland. It is intimately associated with the nodose 
ganglion and sends a contribution to the pharyngeal ramus of the vagus nerve and a ramus communicans to the first cervical nerve. Other comnections to the cranial nerves were infrequent and variable.

2. The vagus nerve and sympathetic trunk are fused in the upper but separate in the lower cervical region. Both nerve trunks are enclosed in a common epineurial sheath.

3. No cardiac plexuses comparable to the human are present in the dog. Instead, a pretracheal plexus receives branches from the craniovagal, recurrent cardiac, left recurrent laryngeal, dorsal cervical, and ventromedial cervical cardiac nerves. The ventrolateral cervical cardiac nerve and the left stellate cardiac nerve form the dorsal ventricular and part of the left pulmonary plexus. The recurrent cardiac nerve forms the main parts of the right and left coronary plexuses. The caudovagal cardiac nerves enter primarily the right dorsal atrial wall. The right stellate cardiac nerves are variable in course and number and enter the dorsal and ventral right atrial walls and right pulmonary plexus. Right and left innominate nerves enter the large arterial walls. The stellate ganglion sends rami communicantes to $\mathrm{C} 7, \mathrm{C} 8, \mathrm{~T} 1, \mathrm{~T} 2$, $\mathrm{T} 3$, and sometimes to $\mathrm{T} 4$, in addition to a vertebral nerve. The ventral limb of the right ansa subclavia usually runs in the sheath of the right vagus nerve. The caudal cervical ganglion is probably comparable to the human intermediate or vertebral ganglion. Besides contributing to the cardiac nerves, it also sends filaments to the phrenic nerve. No cardiac nerves below the stellate ganglion were observed.

4. The ventral gastric nerve, shorter than the dorsal, sends branches to the liver and ventral surface of the stomach, and anastomotic filaments to the plexus on the fundic and cardiac branches of the left gastric artery. The dorsal gastric nerve sends branches to the dorsal surface of the stomach. It also contributes to the celiacomesenteric plexus and to the plexus on the proximal portion of the left gastric artery. In $50 \%$ of the specimens the dorsal gastric nerve sends branches 
to the liver. Filaments of the dorsal gastric nerve can be followed into the hepatic and cranial mesenteric plexuses.

5. The stomach not only receives branches from the plexuses on the gastric and epiploic arteries but also direct filaments from the gastroduodenal plexus which enter the pyloric portion of the stomach. The pancreas receives its supply from the plexuses on the splenie, pancreatic, and gastroduodenal arteries with additional direct contributions from the hepatic plexus. The common bile duct receives branches from the plexuses on the branches of the gastroduodenal and cystic arteries. The gall hladder receives filaments from the plexuses on the cystic and branches of the hepatic artery. The adrenal gland receives its imnervation from the celiac, aorticorenal, and splanchnic ganglia, and direct filaments from the thoracic splanchnic nerve. The renal plexus is formed by the aorticorenal and renal ganglia. A proper and a left accessory gonadal plexus are connected with the intermesenteric plexus. An accessory left gonadal ganglion is more often present than a proper ganglion. Tho intermesenteric plexus reccives branches from the second, third, and 4th, and sometimes first lumbar splanchnic nerves. It sends filaments into the adventitia of the abdominal aorta.

6 . The single thoracic splanchnic nerve emerges from the sympathetic trunk at the 13th thoracic level and terminates in a splanchnic ganglion. The first lumbar splanchnic nerve sends filaments to the aorticorenal and cranial mesenteric ganglia and intermesenteric plexus. The second lumbar nerve enters either the cranial mesenteric ganglion or the intermesenteric plexus, and sometimes sends filaments to the renal plexus and aorticorenal ganglion. The third lumbar splanchnic nerve enters the intermesenteric plexus and sometimes sends branches to the second lumbar nerve, and cranial mesenteric, accessory, or proper gonadal ganglia. The th lumbar splanchnic nerve enters the intermesenteric and proper gonadal plexuses. The 5th lumbar nerve enters the caudal mesenteric ganglion directly. Splanchnic branches from the 6 th and 7 th lumbar levels are variable or absent. Fusion of the 
lumbar sympathetic trunks usually occurs at the 7 th lumbar level.

7. The hypogastric and pelvic nerves unite to form a pelvic plexus. An anastomosis occurs between the hemorrhoidal plexuses on the ventral surface of the rectum. A few filaments from the hemorrhoidal plexuses also compet with the sympathetic plexus on the hemorrhoidal ressels, indicating that the sacral parasympathetic fibers may ascend in the sympathetic periarterial plexus. Sacral parasympathetic branches also ascend on the dorsal and ventral walls of the rectum. The pelvic plexus of the female is similar to that of the male. Few filaments were found to enter the adrentitia of the iliac vessels.

8. Gray rami communicantes are sent to all the sacral spinal nerves and small filaments to the sacral artery. No "ganglion impar" could be found.

\section{LITERATLRE (TTEI)}

Bradery, O. C. 1948 Topogmaphical Anatomy of the Ireg. Oliver and Boyd, London and Edinburgh.

Dowglablo, X. D. 1928 The esophageal nerves of the dog. Ztsehr. f. Anat. u. Entwicklungsgescll., $83: 591-595$.

Ellenefrger, W., AN1 II. PAUM 1891 Anatomie des Humles. Verlag vol Paul Parey, SW., 10 Hedemanstrasse, Berlin, 563-569.

Finkelsthix, A. 1880 Der Nervus depressor hein Mensilen, Kaninehen, Hunde, bei der Katze und dem Pferde. Arch. f. Anat. und Physiol, $245-252$.

Hitsabeck, J. R., AND F. C. Hull 1950 Anatomy of the thoracic ragus in the dog and a technique for its interruption. Proc. Soc. Exp. Biol. and Merl., 7.9: 633-637.

IoNESCO, D., AND M. ENACHEscU 1928 Tntersuchungen bei Säugeticren und Menschen über die aus dem Brustgrenzstrang des Sympathicus unterhall des Ganglion stelatum entsprungenen Herznerven. Ztsehr. f. Auat., $85: 476-478$.

Kexg, L. B. 1893 The cardiac nerves of the dog. J. Physiol., 14: 467-478.

Kuxtz, Albfrt 1945 The Autonomic Nervous System. Lea and Febiger, Philadelphia, 26-27.

L.Anseli, O. 1953 In Morris' Human Anatomy. Ed. by J. Parsons Sehaeffer. The Blakiston Co., Philadelphia, See. VIII, 1199-1200.

I.EARmonth, J. R., AND J. MARkowitz 1929 Studies on the function of the lumbar sympathetic outflow. I. The relation of the lumbar sympathetic outflow to the sphincter ani internus, Am. J. Physiol., 89: 686-691. 
MCCREA, E. D'ARCy 1925 The abdominal distribution of the vagus nerve. J. Anat., London, 59 : 18-40.

Medowar, J. L. 1927 Die Nerven des Uterus und der Vagina des Hundes. Ztsehr. f. Anat., $86: 776-785$.

Mehler, W. R., J. C. Fischer ANd W. F. Alexander 1952 Anatomy and variations of the lumbosacral sympathetic trunk in the dog. Anat. Rec., 113: $421-436$.

Mrller, M. F. 1949 Guide to the Dissection of the Dog. Edwards Bros., Ann Arbor.

Mrtcheld, G. A. G. 1935 The innervation of the distal culon. Edinburgh Med. J., $42: 11-19$.

Nonidez, José F. 1931 Innervation of the thyroid gland. II. Origin and course of the thyroid nerves in the dog. Am. J. Anat., 48: 299-329. 1935 The aortic depressor nerve and its associated epithelioid body, the glomus aorticum. Am. J. Anat., 57: 259--260.

1937 Distribution of the aortie nerve fibers and the epithelioid bodies (supracardial "paraganglia") in the dog. Anat. Rec., 69: 299-313.

1939 Studies on the innervation of the heart. Am. J. Anat, $65: 361-401$.

Schabadasch, A. 1926 Die Nerven der Harnblase des Hundes. Ztschr. f. Anat., $86: 730-754$.

SCHMidT, C. A. 1933 Distribution of the vagus and saeral nerves to the large intestine. Proc. Soc. Exp. Biol. and Med., 30(6): 739-740.

Schurawlew, A. N. 1827 Die Herznerven des Hundes. Ztschr. f. Anat., $86: 653-697$.

TELFord, E. D., AND J. S. B. STOPFord 1934 The autonomic nerve supply of the distal colon. Brit. Med. J., 1: 572-574.

Trumble, H. C. 1934 The plan of the visceral nerves in the lumbar and sacral outflows of the autonomic nervous system. Brit. J. Surg., 91 : 664-676.

VAN DEN BRoEK, A. J. P. 1908 Untersuchungen über den Bau des svmpathischen Nervensystems der Säugetiere. Theil I, Morph. Jahrb., 3r: 229-233. 